\title{
SINGULAR NO BRASIL DO SÉCULO XIX
}

\author{
Maria Stella Orsini*
}

\begin{abstract}
RESUMO
Este artigo focaliza a vida e a obra da primeira dramaturga brasileira, Maria Angélica Ribeiro (1829-1880). A análise de uma de suas peças propiciou a reflexāo sobre dois aspectos relevantes para a pesquisa social e artística: 1. a expressiva participaçāo feminina - a nível profissional - em uma sociedade patriarcal; 2, o retrato de um período da sociedade brasileira e a análise de um tema tabu: a dominasāo social e sexual do homem branco sobre a escrava negra. A imagem desta, até então estudada sob uma perspectiva masculina, a partir de Maria Angélica Ribeiro começou a ser abordada, na literatura dramática, sob uma óptica feminina, resultando na denúncia do social mediante o sexual.

Unitermos: Dramaturga - Literatura dramática - Sociedade patriarcal - Dominação social e sexual
\end{abstract}

\section{Introduçāo}

Causa estranheza a inexistência de estudos que analisem o talento de brasileiras que, ao longo do século XIX, se dedicaram ao campo da criação teatral e que, de certa forma, se destacaram como representantes de uma vanguarda cultural. Em contrapartida, a história do teatro brasileiro desse período registra biografias laudatórias de algumas intérpretes, como é o caso de Estela Sezefreda, Ismênia dos Santos, Apolônia Pinto, Itália Fausta e outras.

Parece que os estudos sobre as primeiras mulheres que escreveram para teatro ficaram proscritos da literatura especializada. A omissão foi uma

(*) Professora Assistente Doutora do Departamento de Comunicaçōes e Artes da Escola de Comunicaçōes e Artes da USP. 
constante por parte dos escritores. O menosprezo foi tão grande que alguns autores chegaram a masculinizar nomes femininos, como ocorreu com Chiquinha Gonzaga, compositora que muito contribuiu para o teatro musicado. ${ }^{1}$ A propósito dessa conspiração de silêncio cabe indagar: por que os historiadores nāo conferiram à mulher o lugar que merecia? Como escrever a história do teatro brasileiro ignorando a participaçāo das autoras de textos teatrais? Como deixar de considerar a literatura dramática sob uma perspectiva feminina?

Até mesmo uma estudiosa do assunto afirmou que:

(...) devemos remontar à fase de Joāo Caetano, que é onde começa nossa arte interpretativa, já que na criadora, as figuras femininas, se hoje são poucas e falhas, naquela fase de nosso desenvolvimento só poderiam ser inexistentes. 2

Entretanto, embora raras, existiram algumas mulheres que no século XIX se dedicaram a essa atividade: Maria Angélica Ribeiro, Júlia Lopes de Almeida, Josefina Álvares de Azevedo, Celina de Azevedo e Maria Eugênia Celso que, apesar da contribuição de ponderoso significado para a história do teatro brasileiro, permaneceram negligenciadas e esquecidas.

Ora, resgatar essas figuras femininas que ficaram envoltas em névoas, quer como pessoas, quer como personalidades artísticas, $e$ tarefa oportuna $e$ urgente.

As peças teatrais que serāo mencionadas neste artigo assinalam a estréia da mulher - Maria Angélica Ribeiro - na história da dramaturgia brasileira. Foram suas as primeiras obras encontradas em número razoável e sobre as quais pode-se afirmar terem sido escritas por uma mulher que realmente percorreu os caminhos da criação teatral. É possível que tenham existido algumas teatrólogas anteriores à aqui analisada; todavia, devem ter sido casos extremamente incomuns e, provavelmente, de mulheres que se dedicaram a essa atividade não como profissionais, mas como amadoras.

\section{Vida}

Maria Angélica Ribeiro nasceu a 5 de dezembro de 1829, em Parati, Estado do Rio de Janeiro.

Para melhor entender a educação dessa escritora é preciso relembrar o panorama cultural e educacional da época em que ela viveu. Ao rastrear o ambiente social de então, historiadores, romancistas, cronistas e viajantes estrangeiros registraram como era descuidada a educação dada às meninas, sobretudo na primeira metade do século XIX. "Mulheres educadas, na linguagem da época, eram aquelas que tinham o privilégio de uma educação

(1) Para esclarecimento desse aspecto consultar as seguintes obras: SILVA, Lafayette. História do teatro brasileiro. Rio de Janeiro, Ministério da Educaçāo e Saúde, 1938. p. 299; SOUSA, J. Galante de. O teatro no Brasil. Rio de Janeiro, MEC/INL, 1960. 2 v. p. 265.

(2) LEITE, Luiza Barreto. A mulher no teatro brasileiro. Rio de Janeiro, Ed. Espetáculo, 1965. p. 12. 
mais aprimorada". 3 Estas costumavam receber liçōes de francês e trabalhos manuais. Das artes, a música era a mais cultivada, já que todas as moças aprendiam a tocar piano. Não eram, de modo geral, iniciadas nas letras e muito menos aprendiam a ler e amar a literatura dramática. E, como se isso já nāo bastasse, havia preconceitos contra o meio teatral, pois os atores e, em especial, as atrizes não gozavam de boa fama.

Sem considerar a situação de submissão, infantilidade e até mesmo de humilhação em que vivia a maioria das mulheres brasileiras do século XIX, é quase impossível valorizar aquelas que ousaram no plano intelectual. É verdade que essas foram exceçōes.

A regra era reclusão, o regime de gineceu, que engordava o corpo e fazia murchar a inteligência; (...) a regra era o casamento muito cedo, as maternidades anuais, a autoridade do marido sucedendo à do pai; a regra era a minoridade prolongada até a velhice. ${ }^{4}$

Não obstante, a educação de Maria Angélica Ribeiro foi diferenciada e nāo pode ser considerada como representativa da média da população, pois vivia em um meio privilegiado do ponto de vista intelectual. Tendo ficado orfā com um ano de idade, foi educada por um amigo de seu pai, Antonio Joaquim Bracet. O tutor proporcionou-lhe um excelente meio onde, cercada de afeto e dedicação, pôde alcançar, pela inteligência e trabalho, uma posição digna e independente. 5 Soube, portanto, aproveitar essa influência benéfica.

Além do talento que se revelou cedo, a grande mola de sua vida foi a presença do culto da justiça que levou-a a lutar pelas causas sociais. Valendo-se de sua veia poética, sempre propôs uma sociedade mais justa e mais humana.

Apesar de nāo ter tido exemplos de mulheres que trilharam uma carreira e, portanto, o modelo feminino de êxito profissional, aos doze anos começou a traçar sua própria caminhada. Escrevia versos e saudaçōes às amigas para presenteá-las em seus aniversários. Foi aperfeiçoando sua arte e chegou a possuir uma pena que manejava com desenvoltura e facilidade. Ainda na juventude colaborou em um periódico da época.

Se na infância encontrou na pessoa do pai adotivo o apoio e o estímulo que utilizou com lucidez, na vida adulta uma outra figura masculina sempre esteve ao seu lado: teve a felicidade de casar-se com um homem de teatroo cenógrafo Joāo Caetano Ribeiro - companheiro e grande incentivador.

(3) BERNARDES, Maria Thereza Caiuby Crescenti. Mulheres educadas - Rio de Janeiro do século XIX - (1840-1890). Tese de doutoramento apresentada no Departamento de Ciências Sociais da Faculdade de Filosofia, Letras e Ciências Humanas da USP, 1983. p. 8.

(4) PEREIRA, Lucia Miguel. As mulheres na literatura brasileira. Anhembi, 17(49):21, dez. 1954.

(5) RIBEIRO, Maria Angélica. Cancros sociais. Rio de Janeiro, Eduardo \& Henrique Laemmert, 1866. p. IX e X. 
Tornou-se mãe de três filhos: duas meninas e um menino. Porém, em maio de 1855 sofreu um duro golpe com o falecimento do filho que deixou-a mergulhada em dor e saudade. Diante de tal adversidade, voltou-se para um mundo de fantasia: seu inconsciente produziu uma soluçāo para o conflito em que vivia, resultando num comportamento criador com que passou a retratar a sociedade da época, transformando a experiência vivida em exercício criativo.

É relevante observar que essa dramaturga viveu de acordo com os padrōes sociais da época; porém, ousou do ponto de vista profissional. Tendo idéias próprias, foi uma pioneira ao romper com certas normas tradicionais e, valendo-se da sua condiçāo de escritora, contribuiu para denunciar as contradiçōes do sistema. Indiscutivelmente sua visão de mundo era bem diferenciada quando comparada à maioria de suas contemporâneas. A análise que fez das condiçōes culturais em que vivia a mulher brasileira em meados do século XIX, reforça o que já foi aqui mencionado, evidenciando nossa situação de inferioridade, principalmente quando, na Europa, as oportunidades oferecidas à mulher eram, comparativamente, bem superiores:

A mulher brasileira, se não quer sujeitar-se ao escárnio dos espirituosos e às censuras mordazes dos sensatos, não tem licença para cultivar o seu espírito fora das raias da música ao piano, e das de algumas frases, mais ou menos estropiadas, de línguas estrangeiras! Nem ao menos, para ler Aimé Martin - Civilizaçāo do gênero humano pelas mulheres!

As européias, sim, essas inteligentes e talentosas podem estudar e escrever; poetar ou compôr dramas e romances; podem satisfazer as ambiçōes de sua alma, ter culto, e conquistar renome...

Entre nós, não, que nada disso se pode dar! O que sai de lavra feminina, ou não presta, ou é trabalho de homem. E nesta última suposição, vai uma idéia oculta e desonesta.

E para que compraríamos, nós mulheres, a fama de sermos autoras de trabalhos que não fossem nossos, se com ela nada ganhamos, nem temos possibilidade de obter lugar ou emprego pelos nossos méritos literários? Valem-nos eles de coisa alguma?

Será pelos lucros?...

Santo Deus! A calúnia nem reflete nisto! 6

Antecipando a participação da mulher em grupos de estudos e debates sobre a produçāo literária da época, ingressou na Sociedade de Estudos Literários do Rio de Janeiro, entidade que congregava jovens que desejavam escrever, discutir suas idéias, enfim aperfeiçoar-se. Aí participou não só de reuniōes a nível teórico, como colaborou efetivamente na Revista Mensal de Ensaios Literários, publicando uma de suas obras.

Vivendo de sua arte, fazendo traduçōes e escrevendo peças teatrais, contribura efetivamente na renda familiar. Distinguiu-se no meio teatral pelo seu talento e pelo seu ecletismo. Pesquisando o enredo de um drama ou a

(6) RIBEIRO, Maria Angélica, op. cit. p. X: 
graça de uma comédia, dava sempre seu toque de originalidade, quer pela argúcia, quer pela perspicácia e sutileza ao abordar temas sociais. 7

Faleceu no dia 9 de abril de 1880 . Viveu apenas cinqüenta anos, mas deixou uma contribuiçāo significativa para a dramaturgia brasileira, embora não tenha tido a oportunidade de ver concretizado o ideal que tanto acalentou: a libertação dos escravos.

\section{Obra teatral}

Fazendo do sentimento a grande força de sua criação, ao concluir sua primeira peça teatral, um drama de cinco atos - Guite ou a feiticeira dos desfiladeiros negros -, por insistência do marido, enviou a obra para o Conservatório Dramático Brasileiro. Tão bem se houve que mereceu do presidente ciessa instituiçāo aprovação pelo trabalho apresentado e palavras de elogio. Iniciava-se aí uma carreira expressiva.

Com vivo entusiasmo e agora com a segurança de um reconhecimento, Maria Angélica Ribeiro presenteou o mundo artístico com mais duas obras no ano de 1856: Paulina e A Aventureira de Vaucloix. Novamente a acolhida por parte do Conservatório foi calorosa, mormente para a segunda peça.

Dificuldades familiares interromperam temporariamente sua atividade de dramaturga. Mas, em 1858, com o intuito de cumprimentar um amigo, ofereceu-lhe um drama em cinco atos. A peça $O$ anjo sem asas, lida e ouvida por muitos, foi louvada pelo então secretário do Conservatório Dramático, um censor austero e rigoroso.

A partir daí sua produçāo tornou-se fértil e profícua, confirmando o dom que possuía, ou seja, enternecer no drama e alegrar na comédia. Surgiram as seguintes peças:

- D. Sancho em Silves (drama histórico);

- As luvas de pelica;

- Gabriela, drama em quatro atos. Foi levada à cena em março de 1863 no Teatro do Ginásio, na cidade do Rio de Janeiro, pela Sociedade Dramática em benefício da atriz Gabriela da Cunha;

- Cancros sociais, drama original em cinco atos. Publicada no Rio de Janeiro por Eduardo Henrique \& Laemmert, em 1866. Representada em maio de 1865 pela empresa dramática de Furtado Coelho, no Ginásio Dramático, cabendo a esse ator o principal papel masculino;

- Cenas da vida artística, comédia;

- Um dia na opulência, comédia em dois atos publicada na Revista Mensal de Ensaios Literários, em 1877;

- Ressurreição do primo Basilio, comédia publicada com o pseud6́nimo "Um Calouro", no Rio de Janeiro, pela Dias da Silva Jr., Typographo, em 1878;

- A cesta da tia Pulquéria, comédia;

- O poder do ouro, comédia;

- Cancros domésticos, comédia;

(7) SABINO, Ignez. Maria Ribeiro. In:- Mulheres ilustres do Brasil. Paris/Rio de Janeiro, Garnier/Livreiro, 1899. p. 202. 
- Opiniāo pública, drama em cinco atos, representado no Teatro S. Luís, Rio de Janeiro, em 1879, pela companhia de Emilia Adelaide;

- Os anjos do sacrifício, drama em cinco atos;

- As proezas do Firmino, comédia em três atos;

- Ouro, ciência, poesia e arte, comédia;

- Deus, pátria e honra, drama em estilo quinhentista referente à época de D. Sancho I.

\section{Cancros sociais}

Ao retratar a vida social brasileira no alvorecer da segunda metade do século XIX, Maria Angélica Ribeiro dramatizou o jogo entre a classe dominante - detentora do trabalho escravo - e a classe dominada, sobretudo a mulher escrava. Esta, duplamente oprimida: pela sua condiçāo de escrava e de mulher. Ao ter seu corpo usado pelo senhor não só como produtora de trabalho e reprodutora de mão-de-obra, mas também como fonte de prazer, tornou-se totalmente dominada. Como conseqüência, esse sistema escravocrata contribuiu para desestruturar o sentido de familia do escravo, dificultando sua organizaçāo social e psicológica. ${ }^{8}$

Apesar de todo o empenho da classe dominante brasileira em desviar a atenção da questão escravista, a partir de 1850 , com a abolição do tráfico de escravos, o tema passou a ser debatido abertamente. Na década de 60 , o problema da escravidão começou a ser considerado com maior profundidade por juristas e passou a ser o centro de interesse de vários poetas e escritores que nāo hesitaram em fazer a denúncia do social mediante o sexual. Em 1859, José de Alencar prestou sua homenagem à raça negra escrevendo a peça Mäe; o mineiro Bernardo Guimarāes, preocupado com o aspecto humanitário da questāo, escreveu A escrava Isaura (1875); A Cachoeira de Paulo Afonso (1876) de Castro Alves retratou bem o sistema patriarcal onde o comportamento licencioso do homem branco com a escrava negra era consentido. Outros escritores como Machado de Assis e Fagundes Varela também deram sua contribuição a tema tão delicado.

Ora, foi exatamente nesse cenário que Maria Angélica Ribeiro foi buscar sua fonte de inspiração, dando à dramaturgia brasileira aquela que é considerada sua melhor obra: Cancros sociais, efetivamente um libelo contra a sociedade escravocrata. Assim, o grande feito dessa mulher foi, apesar de viver na corte, em meados do século XIX, desafiar a sociedade da época ao abordar um tema tabu: dominação social e sexual do homem branco sobre a escrava. Ademais, a situação de humilhação da escrava era até então abordada em prosa e verso segundo o ponto de vista masculino. Com muita coragem, Maria Angélica Ribeiro apresentou a problemática sob uma óptica feminina. Fazendo a ação de sua peça desenrolar-se no Rio de Janeiro, no ano de 1862, possibilitou que as vozes femininas mantidas em silêncio pudessem ser ouvidas e manifestassem suas intençōes de estigmatizar a sociedade escravocrata.

(8) SANT'ANNA, Affonso Romano de. $O$ canibalismo amoroso. Sāo Paulo, Brasiliense, 1985. p. 47. 
Procurando ressaltar o mal que o preconceito pode acarretar, a autora descreveu uma familia feliz e bem estruturada, constituída de Eugênio - que desconhecia suas origens, ignorando quem seriam seus pais - $a$ a esposa Paulina e a filha Olympia. Desejando presentear a filha no dia em que completava dezesseis anos, Eugênio resgatou uma escrava, Martha. Surpreso e atônito, descobriu que essa cativa era sua própria mãe. A autora mostra o conflito psicológico em que se debate o personagem Eugênio diante do julgamento social que teria de enfrentar, caso a reconhecesse publicamente, além do estigma que pairava entre os que não nasciam homens livres. Ao procurar ressaltar a personagem do Visconde de Medeiros como um produto da sociedade escravocrata, representando uma figura negativa, de má índole, incapaz de se regenerar, a autora atribuiu à personagem negra - Martha - sublimes qualidades humanas que destacam ainda mais seu papel de vítima da perfídia do vilāo. O homem que a seduziu, prometeu casamento e depois repudiou-a, renegando o próprio filho.

Lançando mão desse recurso maniqueísta, a autora conseguiu levar para - palco a degradante condição da mulher escrava. Consoante com os padröes sociais da época, o conflito começa a ser solucionado na figura generosa, bondosa e digna do Barāo de Maragugipe que assume a paternidade de Eugênio. A intenção da autora foi fazer uma defesa da mulher e da criança nascida da uniāo entre um branco e uma escrava, bem como denunciar uma sociedade hipócrita e preconceituosa. Diante do desespero de Eugênio com a possível rejeição e perda da honra, caso as pessoas de seu meio social viessem a saber que era filho de uma escrava, o Barāo assim argumentou:

Da tua honra, não! Se nasceste escravo, nāo deixas por isso de ser honrado. Não é a condição que desonra o homem, são os seus próprios atos!

Numa perspectiva feminina, a autora analisou os efeitos que podem gerar a chegada de uma outra mulher num lar bem-estruturado. Ciumenta, desconhecendo a verdade, a esposa de Eugênio torna-se insegura, ferina, chegando mesmo a querer expulsar a intrusa da casa.

Como dramaturga romântica, procurou solucionar bem o conflito armado e encontrou um final feliz. Para tanto introduziu uma personagem-Mathilde - que, pelos laços de amizade que a uniam à família, conseguiu lidar com o problema com tato e sutileza. No desfecho, Martha é reconhecida como a mãe de Eugênio, ficando assim patente a vitória da verdade sobre o preconceito social.

Conciliando o tema da escravidão com o mito da maternidade, a autora conseguiu o aplauso do público em maio de 1865, quando Cancros sociais foi encenada pela empresa dramática de Furtado Coelho, no Ginásio Dramático do Rio de Janeiro. Coroando esse êxito profissional, veio também a palavra daquele que é considerado como provavelmente o melhor crítico teatral brasileiro do século XIX, Machado de Assis:

O nome da Sra. D. Maria Ribeiro, não é desconhecido do público. Representou-se há tempos no Ginásio um drama de sua composição intitulado Gabriela, e oferecido à nossa primeira artista dramática. 
O longo tempo que mediou entre a sua primeira peça e a última, prova uma coisa em favor da autora: é que ela não se atira à composição sôfrega e precipitada; julga melhor para o seu nome caminhar devagar e refletidamente. Para nós é já um motivo de simpatia.

Há, com efeito, entre Gabriela e Cancros sociais, uma notável diferença, um incontestável progresso. A māo incerta no primeiro tentame, é agora mais segura, mais conscienciosa; a autora desenha melhor os caracteres, pinta melhor os sentimentos; a ação aqui é mais natural, mais dramática, mais sustentada; as situaçōes mais bem concebidas e os diálogos mais fluentes.

O novo drama é ainda um protesto contra a escravidāo.

Apraz-nos ver uma senhora tratar do assunto que outra senhora de nomeada universal, Mrs. Beecher Stowe, iniciou com mão de mestre.

(...)

A última cena do $2^{\circ}$ ato, entre o filho e a mãe, parece-nos a mais bela cena da peça. Louvamos com franqueza, criticaremos com franqueza.

A ação que interessa e prende, de ato para ato, falece um pouco no último; o estilo ressente-se de falta de unidade; o diálogo, em geral fluente e natural, peca às vezes pela intervenção demasiada de metáforas e imagens; há algumas cenas, mas poucas, que nos parecem inúteis; e a autora deve ter presente este preceito de arte: - toda a cena que nāo adianta à ação é uma superfluidade.

Feitos estes reparos ligeiros, resta-nos aplaudir do íntimo d'alma a nova obra da autora de Gabriela, cujo talento está recebendo do público legítimos sufrágios. 9

Recebido em 24 de março de 1988.

\section{ABSTRACT}

This article focuses upon the life and work of the first female Brazilian playwright, Maria Angelica Ribeiro (1829-1880). The analysis of one of her plays allows us to reflect upon two relevant aspects of social and artistic research: 1. the significant feminine participation - at a professional level - in a patriarchal society; 2. the profile of a period of the Brazilian society and the analysis of a theme that is taboo: the social and sexual domination of the white man over black female slave, an issue that up until then had always been studied from a male perspective. After Maria Angélica Ribeiro, this issue started being approached from a female perspective in dramatic literature, which resulted in the use of the sexual order as a means of denouncing the social order.

Key-words: Playwright - Dramatic literature - Patriarchal society - Social and sexual domination

(9) MACHADO DE ASSIS. Crônicas. Rio de Janeiro, Jackson, 1955. p. 391-2. 